\title{
CONGESTION ON THE INFORMATION SUPERHIGHWAY: DOES ECONOMICS HAVE A WORKING PAPERS PROBLEM?
}

Lester R. Lusher

Winnie Yang

Scott E. Carrell

Working Paper 29153

http://www.nber.org/papers/w29153

\author{
NATIONAL BUREAU OF ECONOMIC RESEARCH \\ 1050 Massachusetts Avenue \\ Cambridge, MA 02138
}

August 2021

No external funding sources were used in conducting this research. The views expressed herein are those of the authors and do not necessarily reflect the views of the National Bureau of Economic Research.

NBER working papers are circulated for discussion and comment purposes. They have not been peer-reviewed or been subject to the review by the NBER Board of Directors that accompanies official NBER publications.

(C) 2021 by Lester R. Lusher, Winnie Yang, and Scott E. Carrell. All rights reserved. Short sections of text, not to exceed two paragraphs, may be quoted without explicit permission provided that full credit, including $(\odot$ notice, is given to the source. 
Congestion on the Information Superhighway: Does Economics Have a Working Papers Problem? Lester R. Lusher, Winnie Yang, and Scott E. Carrell

NBER Working Paper No. 29153

August 2021

JEL No. I2,J01

\section{ABSTRACT}

Publishing takes a long time in economics. Consequently, many authors release "working" versions of their papers. Using data on the NBER working paper series, we show that the dissemination of economics research suffers from an overcrowding problem: An increase in the number of weekly released working papers on average reduces downloads, abstract views, and media attention for each paper. Subsequent publishing and citation outcomes are harmed as well. Furthermore, descriptive evidence on viewership and downloads suggests working papers significantly substitute for the dissemination function of publication. These results highlight inefficiencies in the dissemination of economic research even among the most exclusive working paper series and suggest large social losses due to the slow publication process.

Lester R. Lusher

Department of Economics

University of Hawaii at Manoa

Saunders Hall 542, 2424 Maile Way

Honolulu, HI 96822

lrlusher@hawaii.edu

Winnie Yang

Department of Economics

University of California, Davis

Davis, CA 95616

wniyang@ucdavis.edu
Scott E. Carrell

Department of Economics

University of California, Davis

One Shields Avenue

Davis, CA 95616

and NBER

secarrell@ucdavis.edu 


\section{Introduction}

Publishing in an economics journal takes a very long time (Hadavand et al., 2021). The mean time from submission to a journal to its acceptance is over two years. The right tail of the distribution is even more staggering, where one in 10 submissions take over three and a half years to acceptance (and over four years to publication). These numbers stand in stark contrast to those from other social sciences (sociology, psychology and political science) and the "hard" sciences, where the mean durations are 13 months and 6 months, respectively. Perhaps most concerning, top economics journals are extremely selective relative to other fields, ${ }^{1}$ and these publication lag statistics ignore any rejections from prior journal submissions, and so the true lifespan of a paper likely stretches across many years. With junior faculty facing tenure clocks as short as five years, this publication lag has large implications for tenure and promotion (Conley et al., 2013). ${ }^{2}$

Such lengthy time to publication has obvious ramifications for the public dissemination of economic research. In nearly all of academia outside of economics, results are not disseminated until after the completion of the peer review process. Economics, on the other hand, does not conform to this norm. Instead, many economists release "working" versions of their papers, presenting preliminary findings to media outlets and at research conferences. Junior faculty will often highlight working papers on their curriculum vitae, and department's hiring and promoting decisions can hinge on a faculty's "pipeline" of working papers. Today, econpapers.repec.org houses over 1 million working papers released across over 5,300 working paper series. The widely-accepted practice of working papers in economics helps bypass its lengthy publication process, but comes with a potential drawback: With no barrier to entry or peer review, the field of working papers could suffer from overcrowding, where each additional paper reduces the visibility and viewership of "competing" research. ${ }^{3}$ Figure 1 suggests this potential issue could be especially pertinent today, where the number of National Bureau of Economic Research (NBER) working papers has steadily increased since 2004, with a drastic increase in releases in 2020 during the pandemic. Despite their ubiquity in economics, only a handful of studies have explicitly investigated the potential benefits and drawbacks of working paper series. ${ }^{4}$

\footnotetext{
${ }^{1}$ The average acceptance rate into the "Top Five" is six percent, whereas the average across three top social science journals and two top natural science journals is 10 percent and 15 percent, respectively (Hadavand et al., 2021).

${ }^{2}$ One reason for the substantial lags in economics reviewing is that journal editors often require multiple sequences of referee reports. Many submissions require up to five revisions before acceptance (Ellison, 2002; McAfee, 2010). Hadavand et al. (2021) provide a detailed exercise into potential culprits for publication lags, and their evidence largely points toward author dilatory behavior in resubmitting revisions.

${ }^{3}$ Several studies have investigated media competition for customer attention and the consequences of "information overload" (e.g. Van Zandt, 2004; Anderson and De Palma, 2009, 2012).

${ }^{4}$ These include Feenberg et al. (2017) who use nearly identical data as our study to investigate ordering effects in weekly releases
} 
In this study, we investigate questions related to the efficiency of the dissemination of economic research via working papers by focusing on the NBER working paper (WP) series. Focusing on the NBER WP series is advantageous for several reasons. First, it is largely regarded as the premier WP series in economics, producing what is likely the most important and impactful research via working papers in the profession. Second, only NBER affiliates are allowed to release papers on the NBER WP series, and NBER affiliates are a highly selected group of economists. Thus, the NBER WP series does possess a barrier to entry that may serve as a substitute for peer review - NBER authors produce papers that are presumably more likely to publish (in better regarded journals) than others. Therefore, any evidence of inefficiencies in the NBER WP series is likely to understate potential inefficiencies in the profession overall.

A final advantage to studying the NBER WP series comes from how the NBER disseminates papers. Throughout the course of each week, NBER affiliates submit their working papers to the NBER without knowing how many other papers have been submitted that week. Then, on Monday of the following week, all submissions are released together and distributed to subscribers. Hence, these weekly releases generate plausibly exogenous variation in the "crowdedness" of the working paper space. As such, any systematic variation within the calendar year in both research productivity and quality can be accounted for in models with higher dimensional time fixed effects (e.g. week-of-year fixed effects), with only idiosyncratic variation remaining.

Overall, our results show strong evidence that the NBER WP series suffers from overcrowding: An increase in the number of weekly released working papers harms each individual paper's outcomes. ${ }^{5}$ In the short run, papers experience significantly fewer abstract views and paper downloads as the number of weekly released WPs increases. This effect is particularly sharp in the first several months of the paper's release. Using data from Altmetric, a company that tracks academic papers across news outlets, blogs, and social media (e.g. Twitter), we find that NBER WPs also receive less media attention when the number of weekly NBER WPs increases. Doubling the number of weekly releases reduces a paper's probability of being covered in the media by over $30 \%$. Further highlighting the importance of these dissemination findings, we find that the NBER WP version of eventually-published papers receives more downloads and abstract views than their published counterpart. Thus, working versions of papers substitute for the dissemination function of the publication process, yet suffer from idiosyncratic variation in the crowdedness of the working paper

of NBER working papers (e.g. papers listed first on the weekly release receive more attention than papers listed second). Novarese and Wilson (2013) study similar hypotheses as Feenberg et al. (2017) but utilize data from Research Papers in Economics (RePEc). A recent working paper from Ziegler (2021) also utilizes NBER working paper data to investigate the extent to which economic research is covered in the media.

${ }^{5}$ Our main sample focuses on working papers released through 2019 in order to avoid any confounding issues with the pandemic. When focusing on publication and citation outcomes, we restrict our sample to papers released through 2017. 
space.

Perhaps most importantly, we also find that publication prospects and citations are harmed from overcrowding. Doubling the number of weekly NBER WPs reduces a paper's probability of publishing by over 4\%. Interestingly, we find no effects on the "quality" of the publishing journal, suggesting a net loss in publishing outcomes for papers when released with a greater number of peer papers. Subsequent citations drop as well: doubling the number of NBER releases reduces citations by approximately $7.5 \%$. Despite the highly selected sample of NBER papers, we find that $26 \%$ of NBER WPs never publish.

Overall, our results highlight a major shortcoming to the profession's dependence on working paper series. Given the exclusivity of NBER, it is likely that non-NBER authors suffer from even steeper challenges in dissemination and crowdedness of working papers.

\section{Data and Institutional Setting}

Our study draws upon three data sets. The first comes from publicly available information on the National Bureau of Economic Research (NBER) website. The NBER is a network of over 1,500 prominent economists who hold academic appointments in North American institutions. These economists are admitted into the NBER through a highly selective process. ${ }^{6}$ The central purpose of the NBER is to disseminate recent, high quality, academic research conducted by economists. The primary method through which the NBER disseminates research is through its working paper (WP) series. Each week, NBER affiliates submit their working papers to the NBER WP series for release on the following Monday. Importantly, when an affiliate submits a paper, they have no knowledge of how many other papers have also been submitted that same week. Each year, over 1,200 WPs are released to over 900 subscribing organizations and many more subscribing individuals. NBER WPs are explicitly not (yet) peer reviewed when they are submitted to the series. For our study, we collect information on the week that each paper was released, the NBER program(s) the paper was submitted under, and a draft of the paper itself.

Second, we match each NBER WP to its webpage on RePEc (Research Papers in Economics). ${ }^{7}$ While the NBER is often regarded as the primary distributor of high quality working papers in economics, RePEC . org is often regarded as the lead distributor of all research (working and published papers) in economics. The website houses about 2.8 million research pieces from 3,200 journals and 5,000 working paper series with over 55,000 registered authors. We use data from RePEc to measure abstract views, downloads, citations, and publication outcomes for each paper.

\footnotetext{
${ }^{6}$ Visit https: / / www . nber.org/about-nber for more information.

${ }^{7}$ The NBER WP series on RePEc can be found at https: / / econpapers.repec.org/paper/nbrnberwo/
} 
Lastly, we use data from Altmetric.com to detect potential media attention for each NBER WP. Altmetric is a company devoted to tracking how much online attention academic articles receive. Altmetric records attention for individual papers across an array of media sources, including the news, blogs, and social media (e.g. Twitter). Their measures additionally include how many people have been exposed to and engage in individual papers. Each NBER WP is provided a public identifier that matches with Altmetric's database. We use the Altmetric database to measure whether a paper received any media attention, how many media sources discussed the paper, and Altmetrics overall "attention score". The attention score is a weighted measure based on the volume of media attention, types of sources (e.g., newspaper vs. Twitter), and the types of authors (e.g., other scholars vs. journal website).

\subsection{Descriptive statistics}

Table 1 presents descriptive statistics for our sample of NBER WPs. In total we observe 16,403 WPs released across 799 weeks from 2004 to 2019. The first panel of Table 1 presents our outcomes of interest. On average, NBER WPs receive 43 abstract views and 35 downloads on RePEc within the first six months of the paper's release. Our next set of outcomes use data from Altmetric. About 15\% of NBER WPs receive some media attention. ${ }^{8}$ When focusing on number of media outlets as an outcome, we see that the majority of NBER WPs that receive media attention do so in only one outlet. We also see a mean and standard deviation of 1.49 and 11.27, respectively, in Altmetric's Attention Score. Turning to publication and citation outcomes, we see that 74\% of NBER WPs subsequently publish, and on average they accumulate over 19 citations on RePEc. ${ }^{9}$

The second panel of Table 1 describes our model covariates. The primary covariate of interest is presented in the first row, "\# of (weekly) NBER WPs," which captures the total number of NBER WPs that were released in a specific week. On average, the NBER WP series releases 23.5 papers every week during our time frame. The data also include information on the authors' prior NBER WP submissions. Overall NBER authors are highly productive: the average number of prior NBER WPs written across authors on a paper's release is roughly 15.5 . NBER WPs on average have 2.5 co-authors, and contain 16,195 words. Finally, each WP is submitted under at least one NBER program. The most popular NBER programs include Economic Fluctuations and Growth (21\%), Labor Studies (21\%), and Public Economics (20\%).

\footnotetext{
${ }^{8}$ This percentage is similar to the media coverage of NBER WPs in Ziegler (2021), who estimates roughly one in 11 NBER WPs receives some media attention within a month of its release.

${ }^{9}$ We focus on papers released through 2017 when focusing on publication and citation outcomes in order to allow adequate time for each NBER WP to publish and accumulate citations.
} 


\section{Econometric Specifications}

Our main specification estimates the following equation:

$$
\mathrm{Y}_{p w y}=\alpha+\beta\left[\ln \left(\mathrm{Num} \_ \text {NBER_WP }\right)\right]_{w y}+\lambda_{w}+\lambda_{y}+X_{p}+\epsilon_{p w y}
$$

where each NBER WP $p$ is released on a specific week $w$ (one through 53) in year $y$ (2004-2019). We consider several outcomes for $\mathrm{Y}$ including abstract viewership and paper downloads (within the first six months of the paper's release), media attention, citations, and publication outcomes. Num_NBER_WP ${ }_{w y}$ measures the total number of NBER WPs that were released on week $w$ in year $y . \lambda_{w}$ and $\lambda_{y}$ capture week and year fixed effects, respectively, while our vector $X_{p}$ include paper level controls such as the word count of the paper, indicators for the NBER programs the paper was submitted under, the number of co-authors, the average number of prior NBER WPs across the paper's authors, and the maximum number of prior NBER WPs across the paper's authors. For ease of interpretation and comparison, we take the natural log of our primary covariate Num_NBER_WP ${ }_{w y}$ and all continuous outcomes (abstract views, downloads, number of media outlets, Altmetric attention score, citations, and publication rank). Hence, if overcrowdedness harms paper outcomes, then we'd expect a negative coefficient for $\beta$.

This twoway fixed effect specification utilizes variation across week-years in the number of released NBER WPs in order to isolate the effect of "crowdedness" on paper level outcomes. Year fixed effects account for aggregate annual trends in the crowdedness of the NBER WP series and NBER WP quality. Week fixed effects account for any weekly, across year trends in how many papers are released and paper quality. This specification, paired with the institutional setting where NBER authors have no knowledge of how crowded the WP space will be when their paper is released, effectively isolates the causal effect of how the number of NBER WPs released each week affects each paper's outcomes. To illustrate the randomness of our primary covariate, in Figure A1 we plot the residuals from a regression of the number of weekly NBER WPs released on year and week fixed effects. We also later conduct several robustness checks and placebo tests, including estimating models with and without paper level controls, replacing year fixed effects with finer time fixed effects, testing various sample year cutoffs, and regressing future week releases on present paper outcomes. 


\section{Results}

\subsection{Abstract views and downloads}

We begin with Table 2 which estimates two variants of specification (1) with the log of abstract views and downloads within the first six months of the paper's release as outcomes. In the first column for each outcome, we consider a model with only week and year fixed effects. In the second column for each outcome, we test the robustness of the estimates to including paper level controls: word count of the paper, indicators for the NBER programs the paper was submitted under, the number of co-authors, the average number of prior NBER WPs across the paper's authors, and the maximum number of prior NBER WPs across the paper's authors. Standard errors are clustered at the week-year level.

Across both model specifications, we first find that an increase in the number of NBER WP weekly releases reduces the number of abstract views for each paper. Estimates are precisely estimated at the $1 \%$ level in the first model and at the 5\% level in the second model. Focusing on the fully specified model in column (2), we estimate that a doubling of the number of weekly releases leads to a nearly $5 \%$ drop in abstract viewership for each paper. A similar pattern holds for paper downloads in columns three and four, though estimates are slightly more noisy: A doubling of weekly releases decreases downloads by nearly $6 \%$ (significant at the $10 \%$ level). Also worth noting are the coefficients on the paper controls: Papers written by more productive authors (as proxied by author prior NBER history) tend to receive more abstract views and downloads. In Figure A2, we estimate our full specification but break down the outcomes into twomonth time intervals to find that the effects of the size of the weekly NBER WP release dissipate over time, disappearing after six months for abstract views and after two months for downloads. ${ }^{10}$

\subsection{Media attention}

In this section, we utilize the Altmetric data to investigate media outcomes for each NBER WP. Table 3 presents the results for three outcomes of interest: 1) Whether the paper received any media attention, 2) the log of the number of media outlets that covered the WP, and 3) the log of overall readership of the WP as measured through Altmetric's Attention Score. The results across all three outcomes are large and statistically significant at the $1 \%$ level, and paint a similar picture as our prior results: When the number of weekly NBER WP releases increases, each paper experiences worsened outcomes. From column (2), we

\footnotetext{
${ }^{10}$ As a heterogeneity test for whether different paper types are more or less likely to respond to the number of NBER WPs released, in Table A1 we reproduce Table 2 but focus on the sample of papers which ex post published. The main estimates from Table A1 are nearly identical to those in Table 2, suggesting the observed overcrowding effect equally harms higher and lower quality papers (as proxied by ex post publication).
} 
predict a 4.7 percentage point drop in the likelihood a paper receives any media attention in response to a doubling of the number of weekly NBER WPs released. Given around 15\% of NBER WPs receive media attention, this translates to an over 30\% drop in the probability of a paper receiving any media attention. The corresponding drop from column (6) in the paper's Altmetric Attention Score, which aggregates overall media attention, is $10.6 \%$.

\subsection{Publication and citations}

We finish our estimations of specification (1) by considering publication and citation outcomes for each NBER WP. These results are presented in Table 4. Once again, we find consistent and robust evidence of negative outcomes for papers when they were released with a higher number of peer NBER WPs. From column (2), we estimate a 2.1 percentage point drop in the likelihood a paper publishes in response to a doubling of the number of NBER WPs released. Given 74\% of NBER WPs eventually publish, this effect is equivalent to a nearly $3 \%$ decrease in publishing probability for each paper. The corresponding estimate in column (4) suggests that citations drop by $7.5 \%$ when the number of weekly NBER WPs doubles. Both of these estimates are precisely estimated at the $5 \%$ level.

To test whether the quality of publication is also affected by overcrowding, we collected journal ranking data from IDEAS aggregated all time journal rankings (ideas.repec.org/top/top.journals. all.html). Approximately $88 \%$ of published papers did so in a "ranked" economics journal. ${ }^{11}$ In the final two columns of Table 4, our outcome is the log of the published paper's journal rank. Across both specifications, we find no evidence that the specific outlets of published journals differed in quality in response to the number of NBER weekly releases. Thus, in total, increasing the crowdedness of the working paper space reduces the likelihood a paper publishes without changing the quality of the journal outlet. ${ }^{12}$

\subsection{Popularity of NBER working papers}

In this section, we provide several descriptive figures on NBER viewership in order to further highlight the importance of the prior results. In Figure 2, we first take the sample of NBER WPs that ex post published. We then plot average (a) abstract views and (b) downloads by month since the NBER WP's release (in red) against the corresponding abstract views and downloads for the published version of the NBER WP since publication (in blue). These results highlight two findings. First, abstract views for NBER WPs are slightly

\footnotetext{
${ }^{11}$ The remaining $12 \%$ published as books, in conference journals, or in journals outside of economics.

${ }^{12}$ In Table A2, We replicate Table 4 while dropping all papers that published in unranked economics journals (i.e. papers that published in books, in conference journals, or in non-economics journals). Our results remain robust to this sample: Increasing the number of weekly NBER WPs reduces each paper's likelihood of publishing and subsequent citations.
} 
higher than their published counterpart. Second, NBER WP downloads drastically outpace downloads from the published version, with twice the number within the first year of release. ${ }^{13}$

These patterns first highlight how working papers have come to substitute for the dissemination function of journal publication. This is perhaps unsurprising - working papers come out prior to the publication, and, thus, carry more novelty with the findings. Moreover, working paper series typically have fewer barriers of access, whereas most journals require some form of subscription or payment. These patterns additionally highlight the importance of working papers overall - if a central purpose of academic research is to disseminate findings, then it is of great importance that we understand how working papers have come to substitute for publications and how efficient working paper series are in reaching audiences.

Another potential concern with a reliance on working papers is that they (typically) have not yet been through a peer review process. Consequently, any academics, media, and policy makers basing their decisions on working papers are doing so on unvetted, potentially less reliable findings. Similar to Figure 2, in Figure 3 we plot a time series of abstract viewership statistics and downloads of NBER WPs by whether the paper ex post published. Interestingly, as quickly as month two for abstract views and month three for downloads, NBER WPs that ex post published receive a greater audience than those that never publish. Assuming readers are more interested in higher quality (more likely to publish) papers, this reveals that prior to publication, readers on average are able to identify higher quality studies. In other words, even though all NBER WPs have equal audiences, those that eventually publish garner more attention. This suggests that readers of the NBER WP series are vetting paper quality on their own, shifting viewership towards higher quality, more likely to publish WPs. Thus, overall there is perhaps less of a concern that working papers have yet to have gone through the peer review process.

\subsection{Robustness checks and placebo tests}

In this section, we consider several robustness checks and placebo tests. First, our primary model estimates week fixed effects, which control for any seasonalities that vary at the week level across all years. This control would not be adequate in situations where there are any season-year specific shocks that both 1) lead to a greater number of NBER WPs released and 2) produce lower quality papers (which inherently experience worse outcomes). For example, from Figure 1 we can see a huge jump in NBER WP releases soon after the outbreak of Covid - if these papers are also systematically lower quality, then week and year

\footnotetext{
${ }^{13}$ One caveat to this juxtaposition is that we rely strictly on viewership within RePEC.org. It is possible that viewers attain working papers from different sources from published papers. For instance, this juxtaposition will undersell viewership of published versions of manuscripts if more people view published articles straight from the journal's website (or through printed versions) compared to viewers of NBER manuscripts straight fromm the NBER website.
} 
fixed effects would not adequately control for this shock. ${ }^{14}$ A similar potential jump can be seen in the Fall of 2007, just after the Great Recession. To account for these potential season-year shocks, in Table A3 and Table A4 we re-estimate specification (1) but replace our year fixed effects with month-year and quarteryear fixed effects, respectively. These models rely on variation in the NBER WP space across weeks within each month-year and quarter-year, respectively, and thus account for any season-year specific shocks, so long as the level of the shock is not finer than the month or quarter levels. The results from these models confirm those from our main findings, and in fact generally produce more precise estimates (e.g. the effects on publishing are significant at the $1 \%$ level from Table A3 and Table A4).

Next, we test the sensitivity of the publishing and citation outcomes to different year cutoffs for our sample. Recall that our primary analyses focused strictly on papers released through 2017 in order to allow at least three years for each paper to be published and accumulate citations. In Table A5, we estimate our full model but consider various year cutoffs, starting with 2015 and ending with the full sample (2019). Our main estimates remain statistically significant across all sample selections. Moreover, estimates slowly attenuate toward zero as the sample includes more recent years, further justifying a focus on earlier years when investigating these outcomes.

Since our data also include author identifiers for each paper, we can also estimate models with "author fixed effects." However, since each paper observation can contain more than one author, and since not all authors of NBER WPs have multiple NBER WPs, as a robustness check, we utilize author information by estimating dummies for each author with two or more papers within our dataset. These dummy variables switch on for each author of a single paper observation. For example, a paper with two authors who wrote multiple NBER WPs will have two dummy variables switch on, one for each of the two authors. A total of 5,574 authors of NBER WPs have written multiple NBER WPs, and so 5,573 dummy variables are estimated. The results from this exercise are presented in Table A6. We find that our results remain robust to this consideration, suggesting different types of authors are not any more or less likely to release their work on weeks with more NBER WPs in total.

As a placebo test, in Table A7 we estimate specification (1) but with the subsequent week's number of NBER WPs released as the main covariate. Assuming no serial correlation, the future crowdedness of the NBER WP space should have no impact on today's paper's outcomes. Indeed, across all seven of our primary outcome variables, we fail to estimate a significant relationship between future NBER WP releases and present NBER WP outcomes.

Finally, an alternate potential explanation of our results is that a greater number of weekly NBER WP

\footnotetext{
${ }^{14}$ Note that our main sample focuses on papers released through 2019 and thus avoids this Covid-specific shock.
} 
releases may be correlated with some other week-level characteristic which itself is harming other paper's outcomes. For example, it may be that on weeks when a superstar economist releases a NBER WP, readers ignore the other NBER WPs (and weeks with a higher number of releases are more likely to contain a superstar paper). ${ }^{15}$ In Table A8, we re-estimate specification (1) but replace our main covariate with a proxy for this hypothesis - for each week, we calculate the maximum number of prior released NBER WPs across that week's authors. The assumption then is that authors who release more NBER WPs tend to be more wellknown. Naturally, this measure will be correlated with our main covariate, the weekly number of NBER WP releases. Still, across our seven outcomes, we only estimate statistical significance at the $10 \%$ level for abstract views and downloads. Estimates for media attention and publication and citation outcomes are precisely estimated zeroes. We thus conclude that our observed effects cannot be attributed to the presence of a single superstar author, and are more likely driven by general crowdedness in the NBER WP space.

\section{Conclusions}

This study examines the efficiency of the dissemination of economic research via working papers. To do so, we utilize data from the NBER WP series, which is largely regarded the premier WP series in economics. The NBER's dissemination process creates a natural experiment where weekly releases generate exogenous variation in the "crowdedness" of the working paper space.

Results show strong evidence that economics working papers suffer from overcrowding: Increases in the number of weekly released NBER WPs harms individual paper outcomes. Papers receive significantly fewer abstract views and downloads, particularly in the first several months of the paper's release. We also find negative effects from overcrowding on media attention, publication prospects, and the number of citations . Doubling the number of weekly NBER WPs reduces a paper's probability of receiving media coverage by $30 \%$, while the chance of publishing decreases by nearly $3 \%$ and the number of citations decreases by $7.5 \%$. We find no effect on the "quality" of the publishing journal, suggesting a net loss in publishing outcomes for papers when released with a greater number of peer papers.

Overall, our results highlight a major shortcoming to the profession's dependence on working paper series. Given to the highly selected nature of NBER affiliates, which creates a barrier to entry to the NBER WP series, our results likely understate the potential inefficiencies in the dissemination of economics research.

\footnotetext{
${ }^{15}$ Such an effect is akin to that of Brown (2011), who finds that the mere presence of Tiger Woods in a golf tournament harms the performance of other golfers. Of course, in our setting papers are not directly competing with each other, and authors have no ability to know which other papers and authors they will be paired with ahead of time.
} 


\section{References}

Anderson, S. P. AND A. De PALma (2009): “Information congestion,” The RAND Journal of Economics, 40, 688-709.

(2012): "Competition for attention in the information (overload) age," The RAND Journal of Economics, 43, 1-25.

BRown, J. (2011): "Quitters never win: The (adverse) incentive effects of competing with superstars," Journal of Political Economy, 119, 982-1013.

Conley, J. P., M. J. Crucini, R. A. Driskill, And A. S. Önder (2013): "The effects of publication lags on life-cycle research productivity in economics," Economic Inquiry, 51, 1251-1276.

Ellison, G. (2002): "The slowdown of the economics publishing process," Journal of political Economy, 110, 947-993.

Feenberg, D., I. Ganguli, P. Gaule, And J. Gruber (2017): "It's good to be first: Order bias in reading and citing NBER working papers," Review of Economics and Statistics, 99, 32-39.

Hadavand, A., D. S. Hamermesh, And W. W. Wilson (2021): "Publishing Economics: How Slow? Why Slow? Is Slow Productive? Fixing Slow?" Tech. rep.

MCAFEE, R. P. (2010): “Edifying editing,” The American Economist, 55, 1-8.

Novarese, M. AND C. M. Wilson (2013): "Being in the right place: a natural field experiment on list position and consumer choice," .

VAN ZANDT, T. (2004): "Information overload in a network of targeted communication," RAND Journal of Economics, 542-560.

ZIEGLER, L. (2021): "What is the Media Impact of Research in Economics?” Tech. rep., Working paper. 
Tables and Figures 
Table 1: Descriptive statistics

\begin{tabular}{|c|c|c|}
\hline & Mean & S.D. \\
\hline & \multicolumn{2}{|c|}{ Outcomes } \\
\hline Abstract views in the first 6 months & 43.33 & 55.16 \\
\hline Downloads in the first 6 months & 35.23 & 36.31 \\
\hline Received any media attention & 0.15 & 0.35 \\
\hline \# of media outlets & 0.15 & 1.21 \\
\hline Altmetric Attention Score & 1.49 & 11.27 \\
\hline Citations $(\mathrm{N}=13,963)$ & 19.05 & 43.28 \\
\hline Publication $(\mathrm{N}=13,963)$ & 0.74 & 0.44 \\
\hline Publication rank $(\mathrm{N}=8,752)$ & 92.7 & 191.42 \\
\hline \multicolumn{3}{|l|}{ Covariates } \\
\hline \# of (weekly) NBER WPs & 23.51 & 8.24 \\
\hline Paper-authors' $\max$ (\# of prior NBER WPs) & 27.21 & 28.83 \\
\hline Paper-authors' mean(\# of prior NBER WPs) & 15.46 & 18.53 \\
\hline \# of co-authors & 2.48 & 1.05 \\
\hline \# of words in manuscript & 16195.06 & 7325.83 \\
\hline \multicolumn{3}{|l|}{ NBER programs: } \\
\hline - Economics of Aging & 0.06 & 0.25 \\
\hline - Asset Pricing & 0.11 & 0.31 \\
\hline - Corporate Finance & 0.10 & 0.30 \\
\hline - Children & 0.08 & 0.26 \\
\hline - Development of the American Economy & 0.06 & 0.25 \\
\hline - Development Economics & 0.06 & 0.24 \\
\hline - Economics of Education & 0.08 & 0.27 \\
\hline - Environment and Energy Economics & 0.06 & 0.24 \\
\hline - Health Care & 0.07 & 0.26 \\
\hline - Economic Fluctuations and Growth & 0.21 & 0.41 \\
\hline - Health Economics & 0.10 & 0.30 \\
\hline - International Finance and Macroeconomics & 0.12 & 0.32 \\
\hline - Industrial Organization & 0.08 & 0.27 \\
\hline - International Trade and Investment & 0.09 & 0.28 \\
\hline - Law and Economics & 0.05 & 0.22 \\
\hline - Labor Studies & 0.21 & 0.41 \\
\hline - Monetary Economics & 0.11 & 0.31 \\
\hline - Public Economics & 0.20 & 0.40 \\
\hline - Political Economy & 0.07 & 0.25 \\
\hline - Productivity, Innovation, and Entrepreneurship & 0.10 & 0.29 \\
\hline - Technical Working Papers & 0.02 & 0.13 \\
\hline Number of NBER WPs & 16403 & \\
\hline Number of weeks & 799 & \\
\hline
\end{tabular}

Notes: Full sample includes all NBER working papers released from 2004 to 2019 . We restrict our sample to papers released through 2017 when investigating publication and citation outcomes. 
Table 2: Abstract views and Downloads in the first 6 months

\begin{tabular}{|c|c|c|c|c|}
\hline & $(1)$ & (2) & (3) & (4) \\
\hline & \multicolumn{2}{|c|}{$\ln (\#$ of Abstract views) } & \multicolumn{2}{|c|}{$\ln (\#$ of Downloads) } \\
\hline $\ln (\#$ of NBER WPs) & $\begin{array}{c}-0.058 * * * \\
(0.022)\end{array}$ & $\begin{array}{c}-0.047 * * \\
(0.021)\end{array}$ & $\begin{array}{c}-0.070 * * \\
(0.032)\end{array}$ & $\begin{array}{l}-0.059 * \\
(0.031)\end{array}$ \\
\hline \# of co-authors & & $\begin{array}{c}0.003 \\
(0.006)\end{array}$ & & $\begin{array}{c}-0.017 * * \\
(0.007)\end{array}$ \\
\hline $\max (\#$ of prior NBER WPs) & & $\begin{array}{c}0.005 * * * \\
(0.000)\end{array}$ & & $\begin{array}{c}0.003 * * * * \\
(0.000)\end{array}$ \\
\hline mean(\# of prior NBER WPs) & & $\begin{array}{c}0.002 * * * \\
(0.001)\end{array}$ & & $\begin{array}{c}0.006^{* * * *} \\
(0.001)\end{array}$ \\
\hline Observations & 16,403 & 16,403 & 16,403 & 16,403 \\
\hline R-squared & 0.362 & 0.446 & 0.053 & 0.155 \\
\hline Week FE & Y & $\mathrm{Y}$ & $\mathrm{Y}$ & $\mathrm{Y}$ \\
\hline Year FE & $\mathrm{Y}$ & Y & $\mathrm{Y}$ & $\mathrm{Y}$ \\
\hline Program FE & & $\mathrm{Y}$ & & $\mathrm{Y}$ \\
\hline
\end{tabular}

Notes: Observations unique at the paper level. The primary covariate of interest "\# of NBER WPs" measures the total number of released NBER WPs during the week that an observed paper was released. Even columns additionally control for manuscript length (in number of words). Standard errors clustered at the week-year level.

$* * * \mathrm{p}<0.01, * * \mathrm{p}<0.05, * \mathrm{p}<0.1$ 


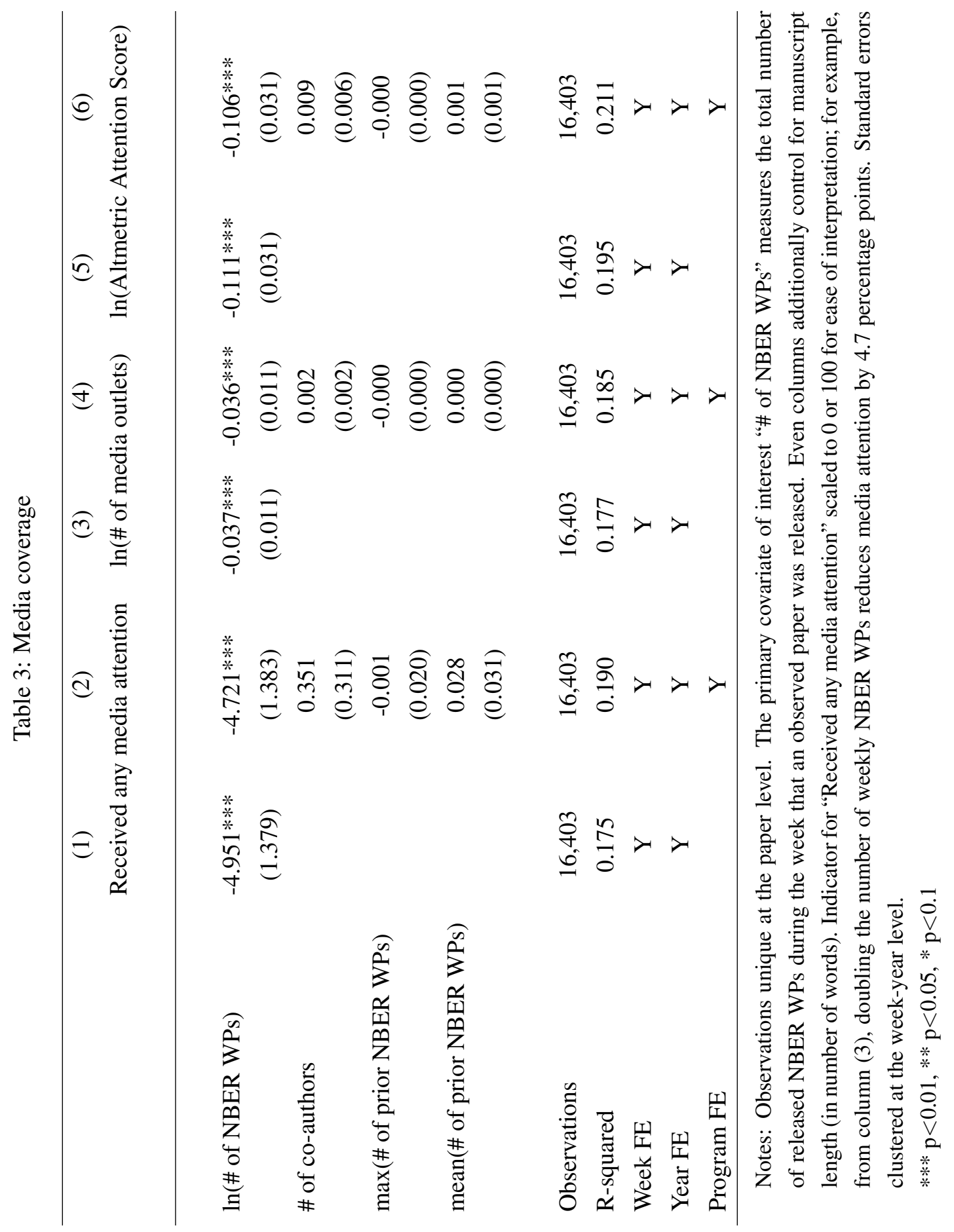




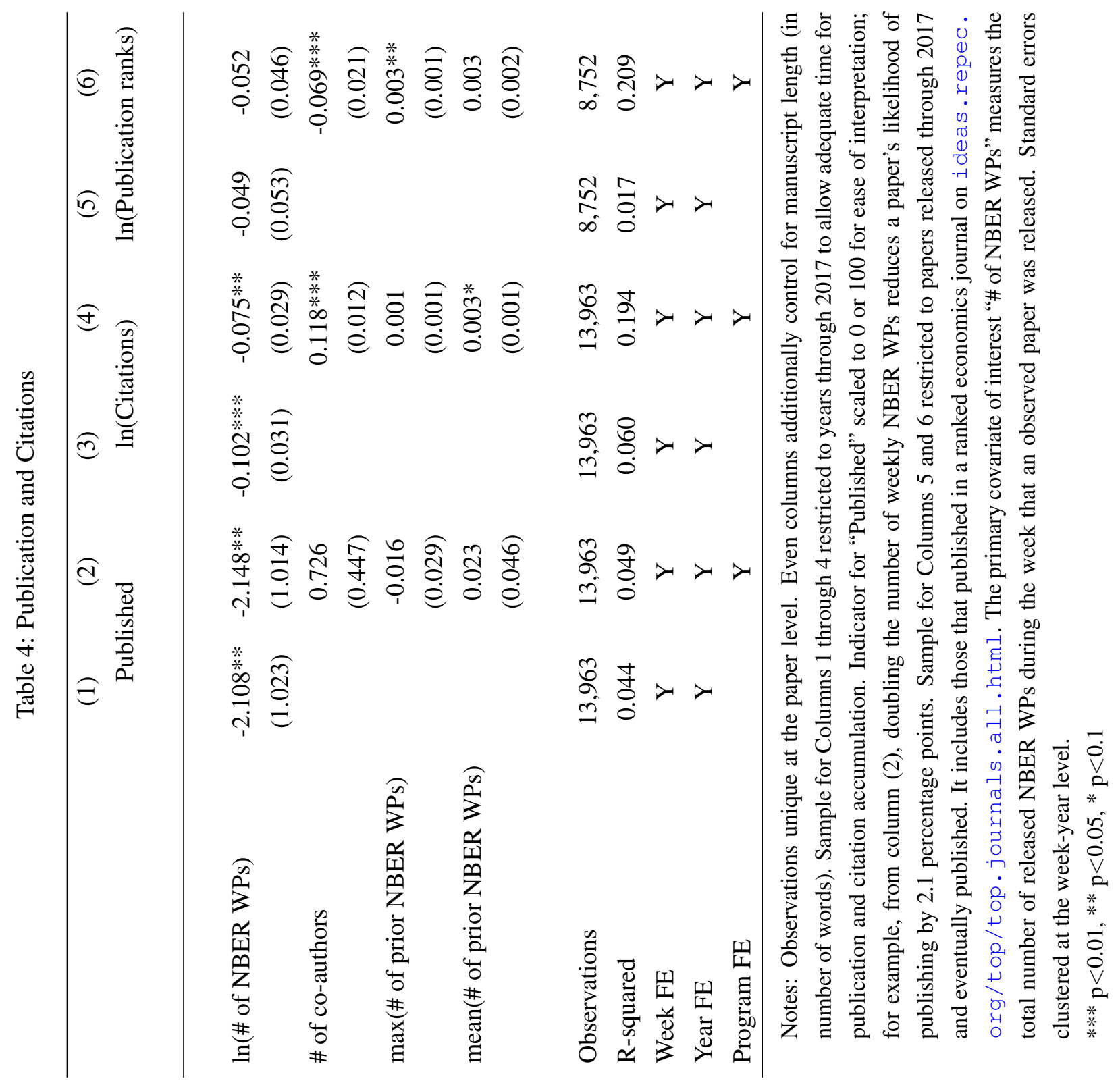


Figure 1: Time series of number of weekly NBER working paper releases

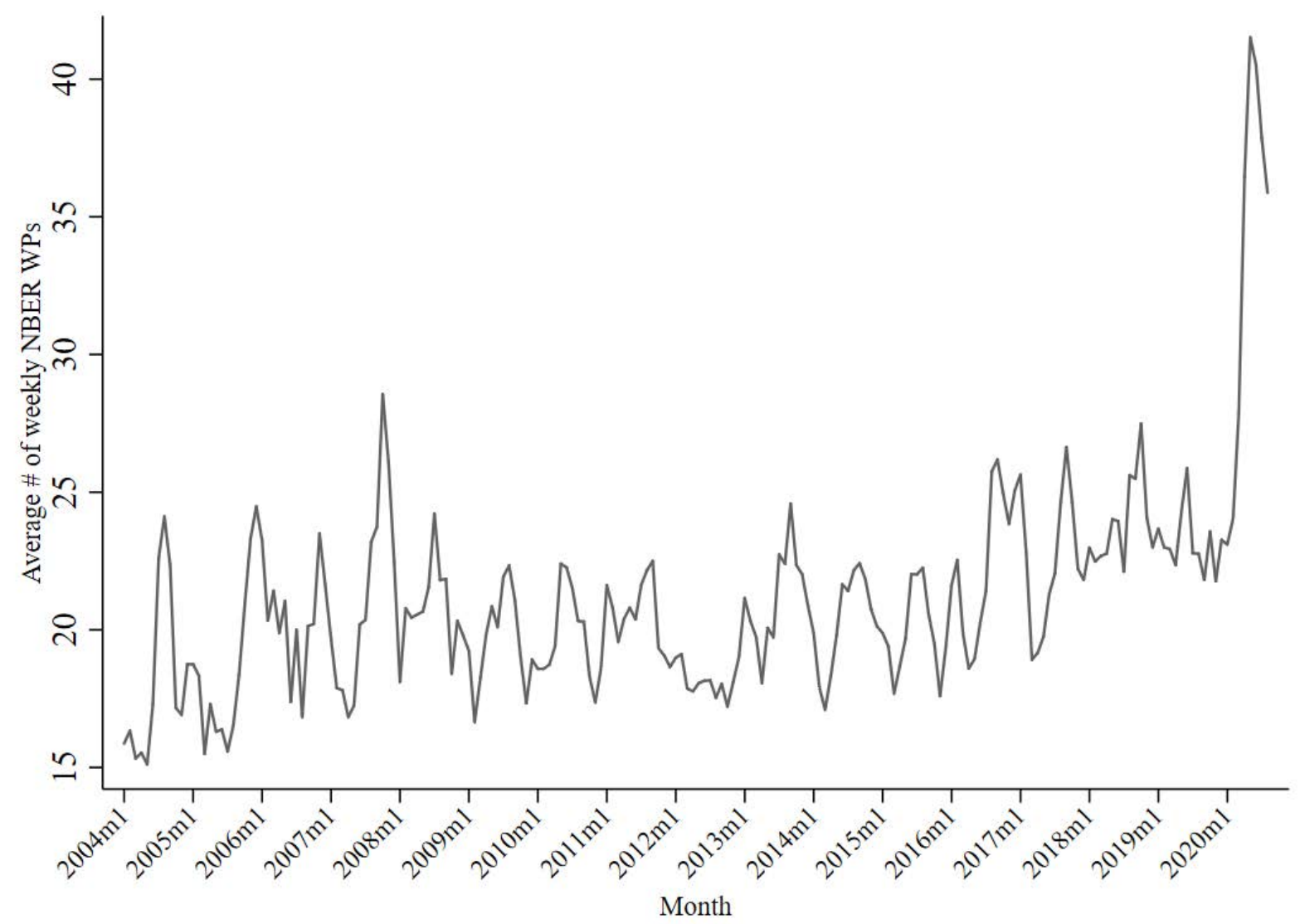

Notes: For each month since January 2004, we first calculate the average number of weekly NBER WPs released. The figure then plots a simple three month moving average of this measure. 
Figure 2: Accumulated viewership and downloads of NBER WPs versus their published counterparts over time

(a) Abstract views

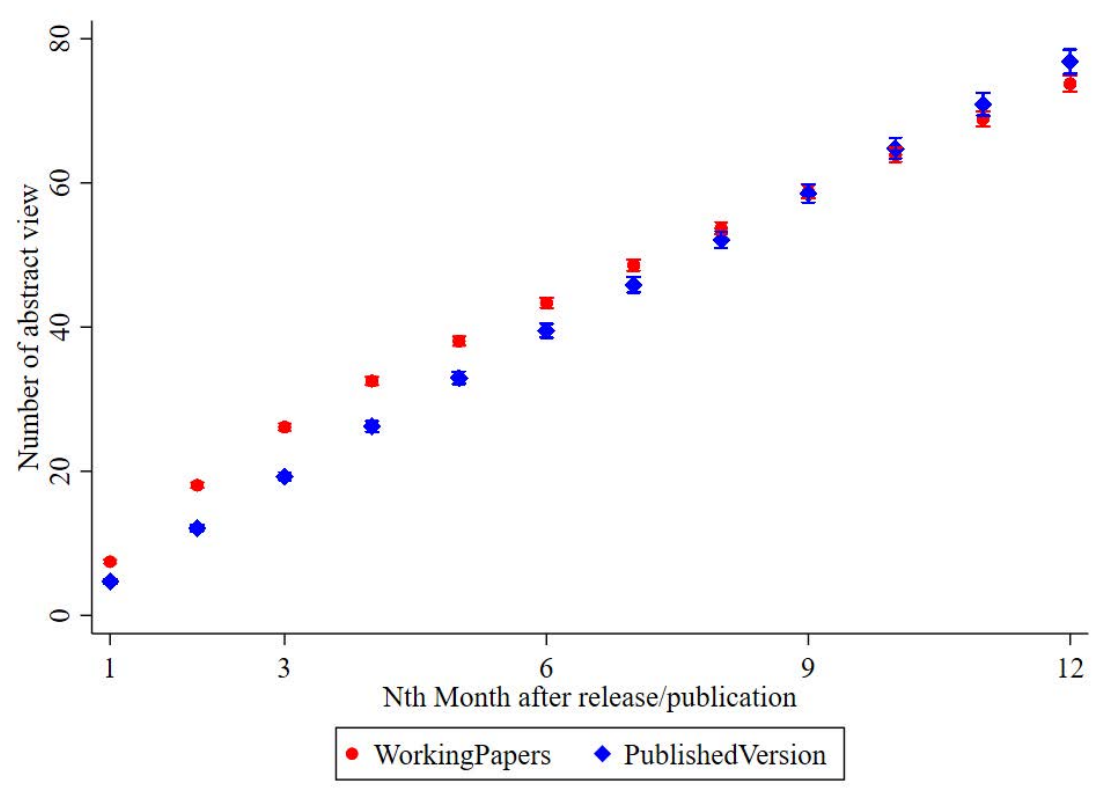

(b) Downloads

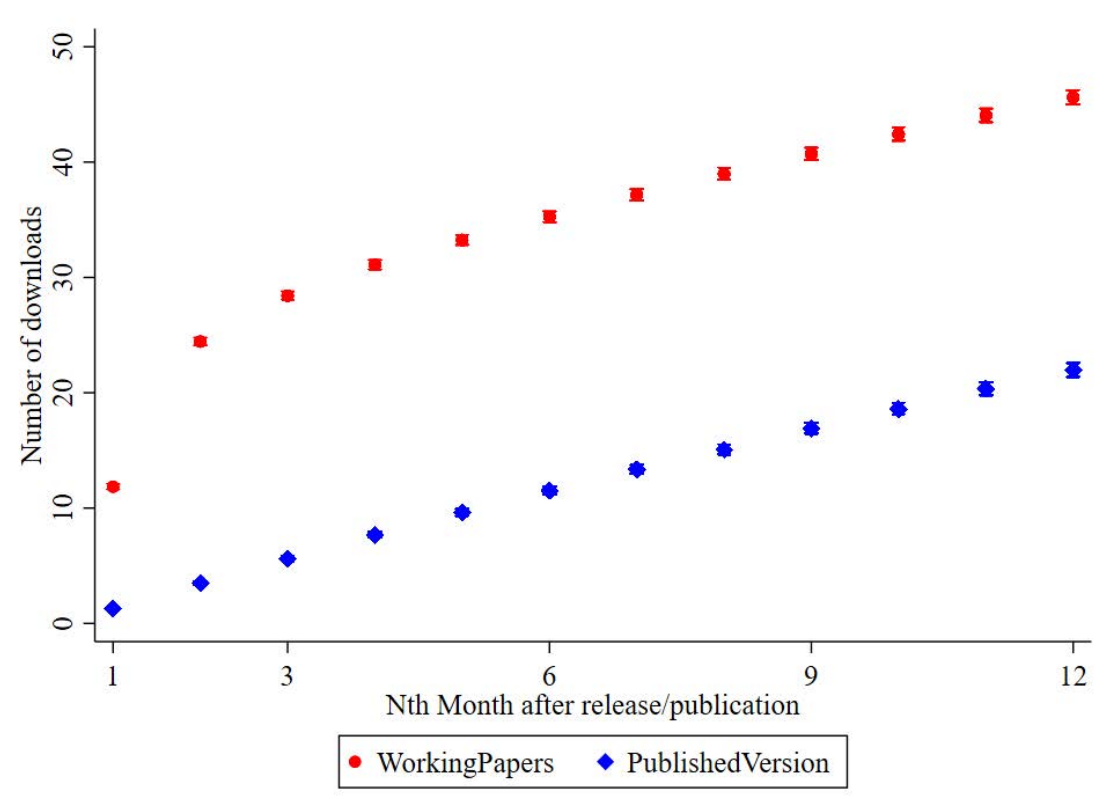


Figure 3: Accumulated viewership and downloads of ex-post published vs. unpublished NBER WPs

(a) Abstract views

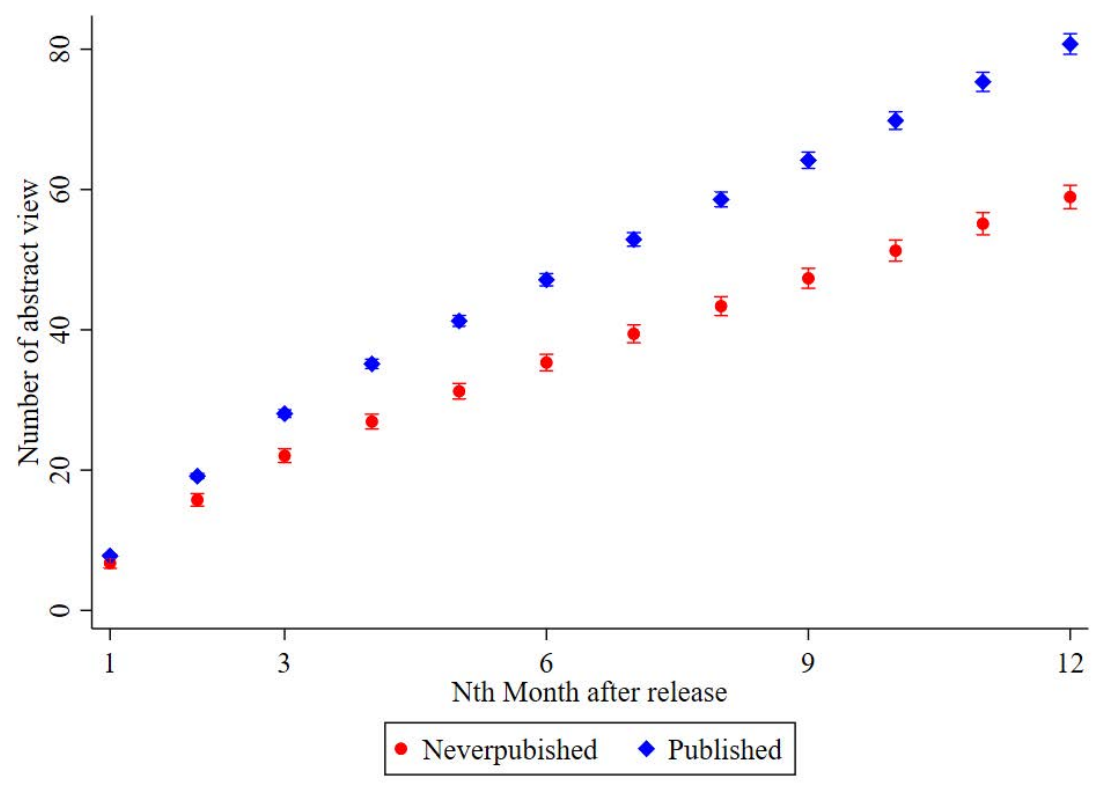

(b) Downloads

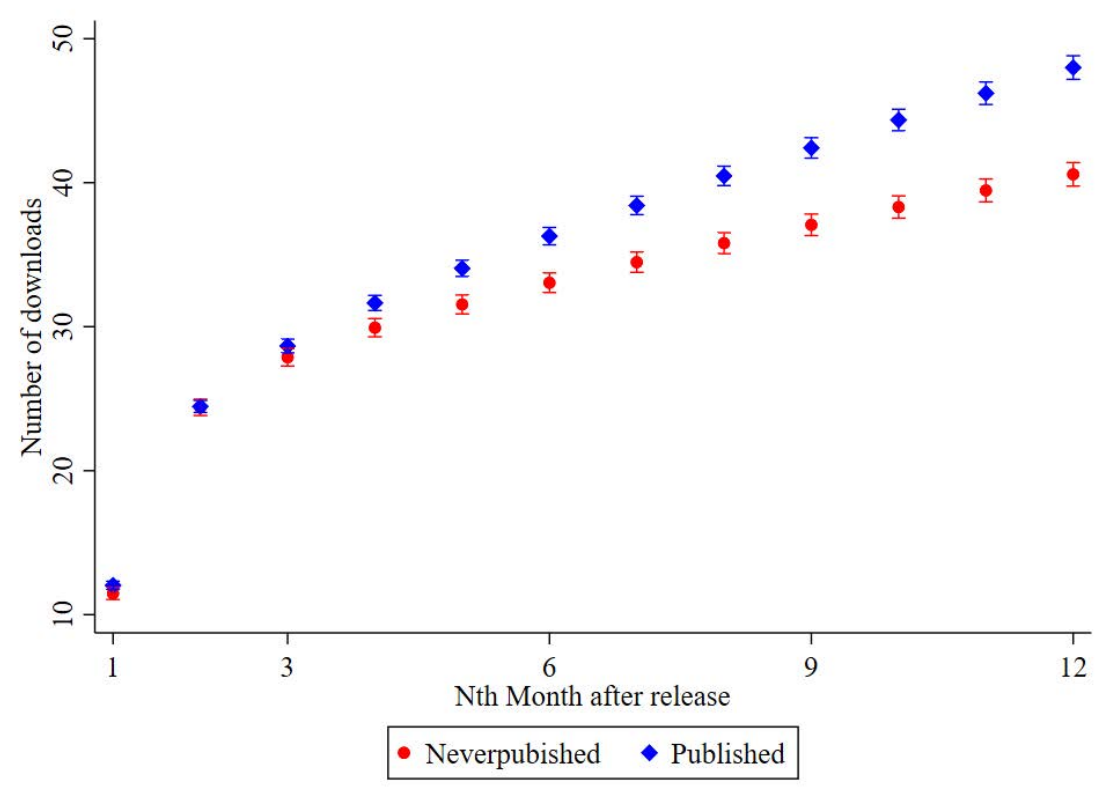




\section{Online Appendix: Additional Tables and Figures}

Table A1: Abstract views and downloads in the first 6 months (Sample: WPs which eventually publish)

\begin{tabular}{lcccc}
\hline & $(1)$ & $(2)$ & $(3)$ & $(4)$ \\
& $\ln (\#$ of Abstract views) & $\ln$ (\# of Downloads) \\
& & & & \\
& & & & \\
ln(\# of NBER WPs) & $-0.057^{* *}$ & $-0.044^{*}$ & $-0.077^{* *}$ & $-0.067^{*}$ \\
& $(0.024)$ & $(0.023)$ & $(0.035)$ & $(0.035)$ \\
\# of co-authors & & -0.002 & & $-0.019^{*}$ \\
& & $(0.007)$ & & $(0.010)$ \\
max(\# of prior NBER WPs) & & $0.005^{* * *}$ & & $0.003^{* * *}$ \\
& & $(0.001)$ & & $(0.001)$ \\
mean(\# of prior NBER WPs) & & $0.002^{* *}$ & & $0.006^{* * *}$ \\
& & $(0.001)$ & & $(0.001)$ \\
Observations & & & & \\
R-squared & 11,153 & 11,153 & 11,153 & 11,153 \\
Week FE & 0.368 & 0.457 & 0.054 & 0.166 \\
Year FE & $\mathrm{Y}$ & $\mathrm{Y}$ & $\mathrm{Y}$ & $\mathrm{Y}$ \\
Program FE & $\mathrm{Y}$ & $\mathrm{Y}$ & $\mathrm{Y}$ & $\mathrm{Y}$ \\
\hline
\end{tabular}

Notes: Observations unique at the paper level. The primary covariate of interest "\# of NBER WPs" measures the total number of released NBER WPs during the week that an observed paper was released. Even columns additionally control for manuscript length (in number of words). Standard errors clustered at the week-year level.

$* * * \mathrm{p}<0.01, * * \mathrm{p}<0.05, * \mathrm{p}<0.1$ 


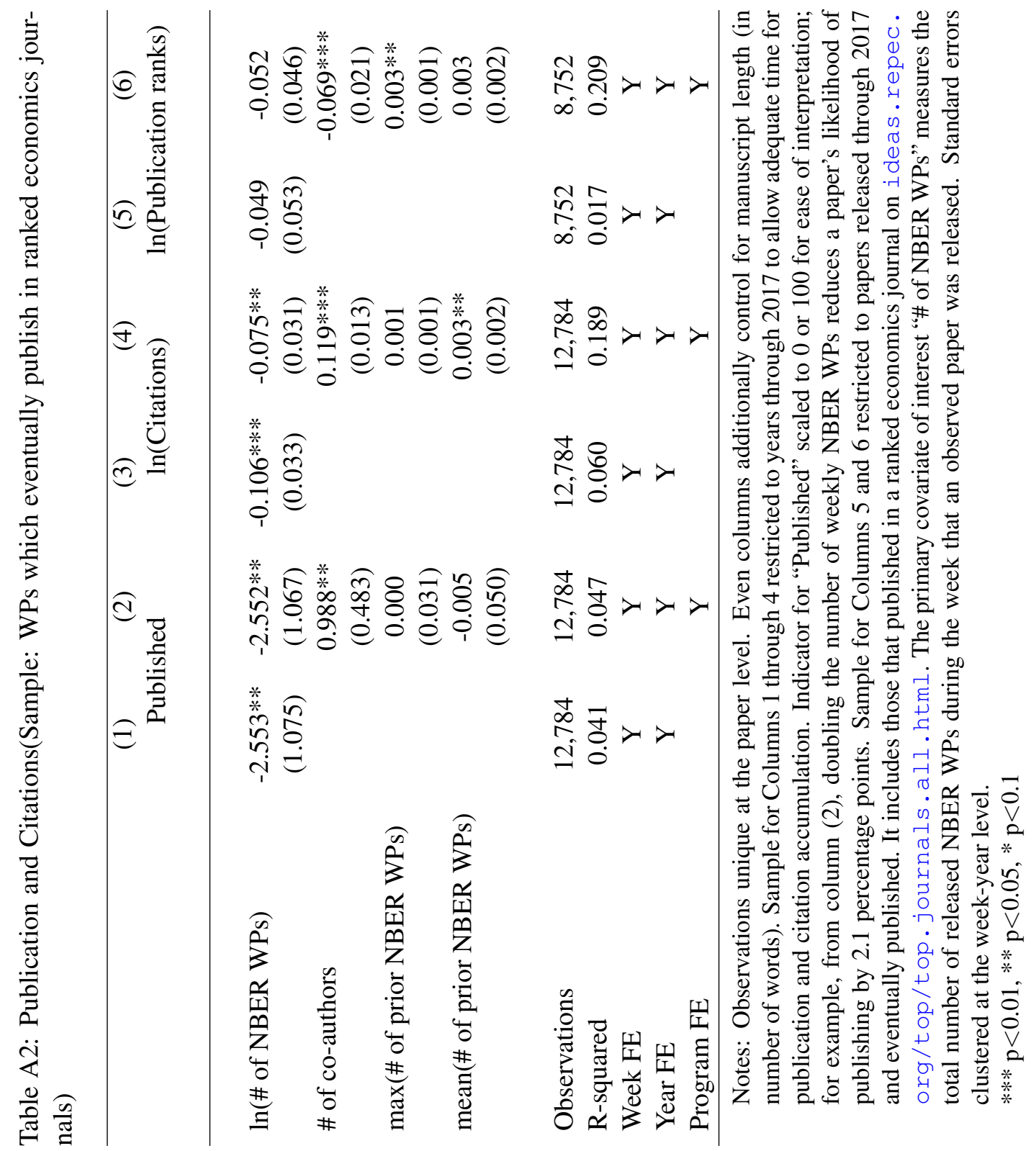




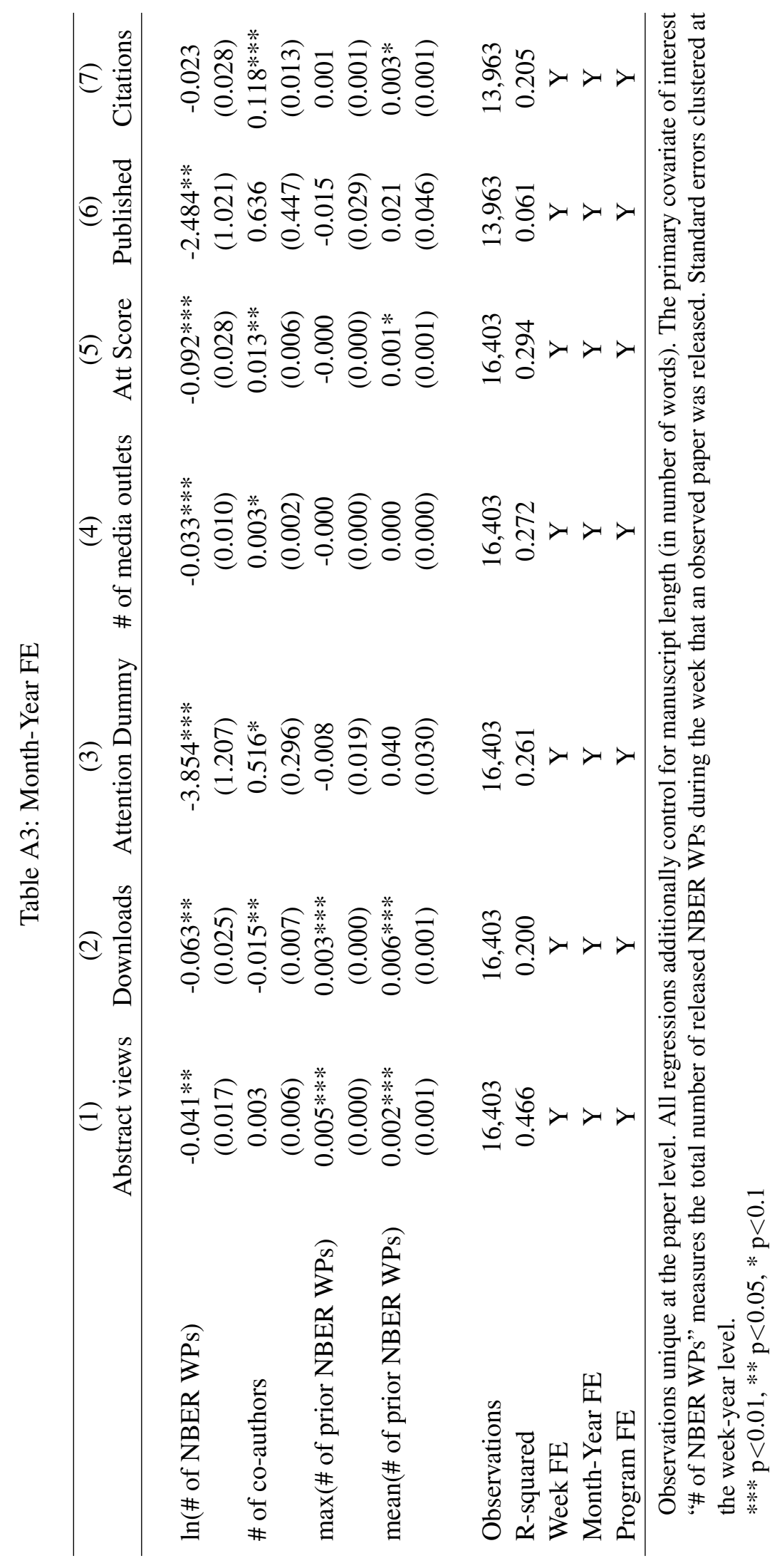




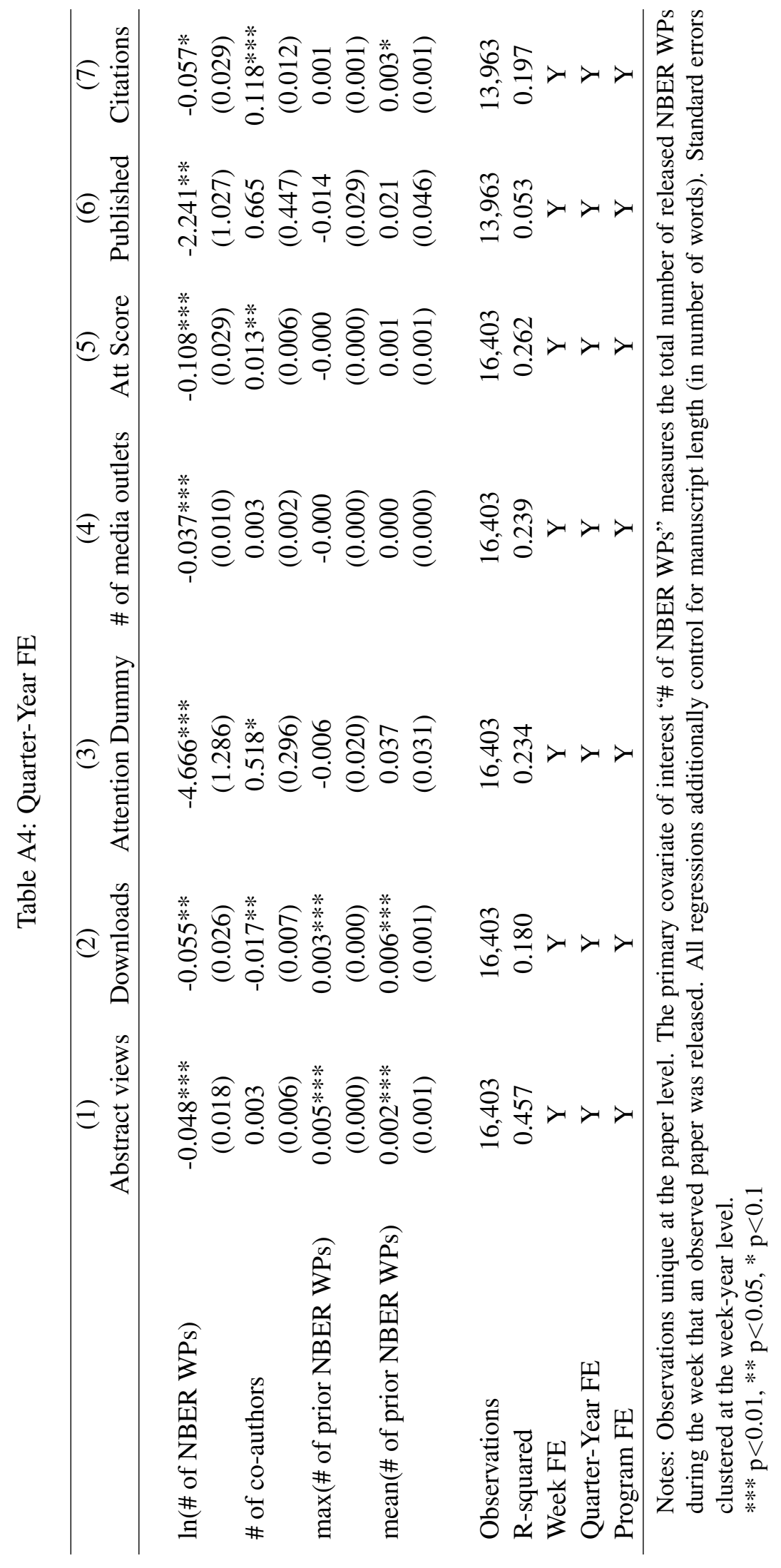




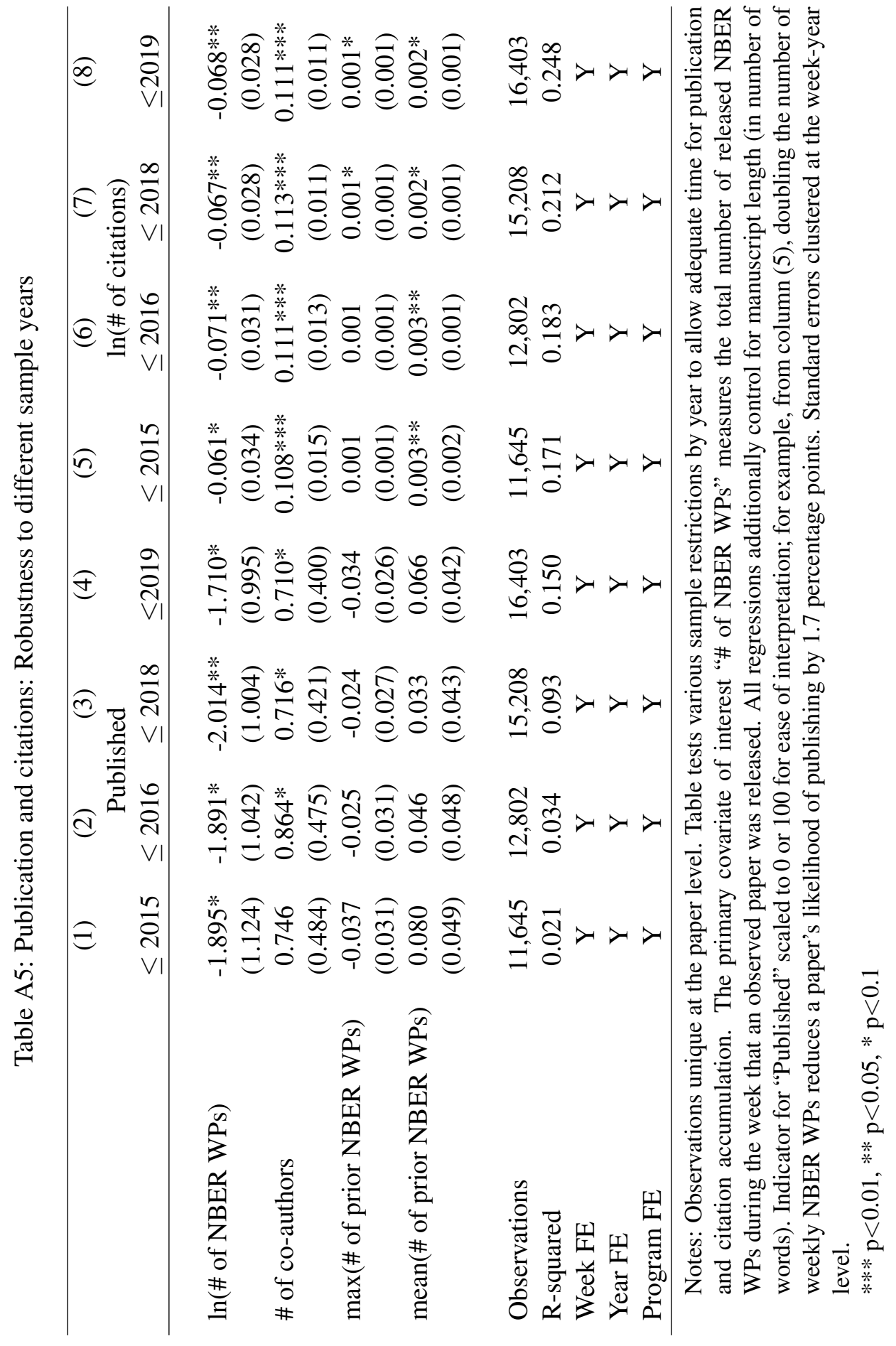




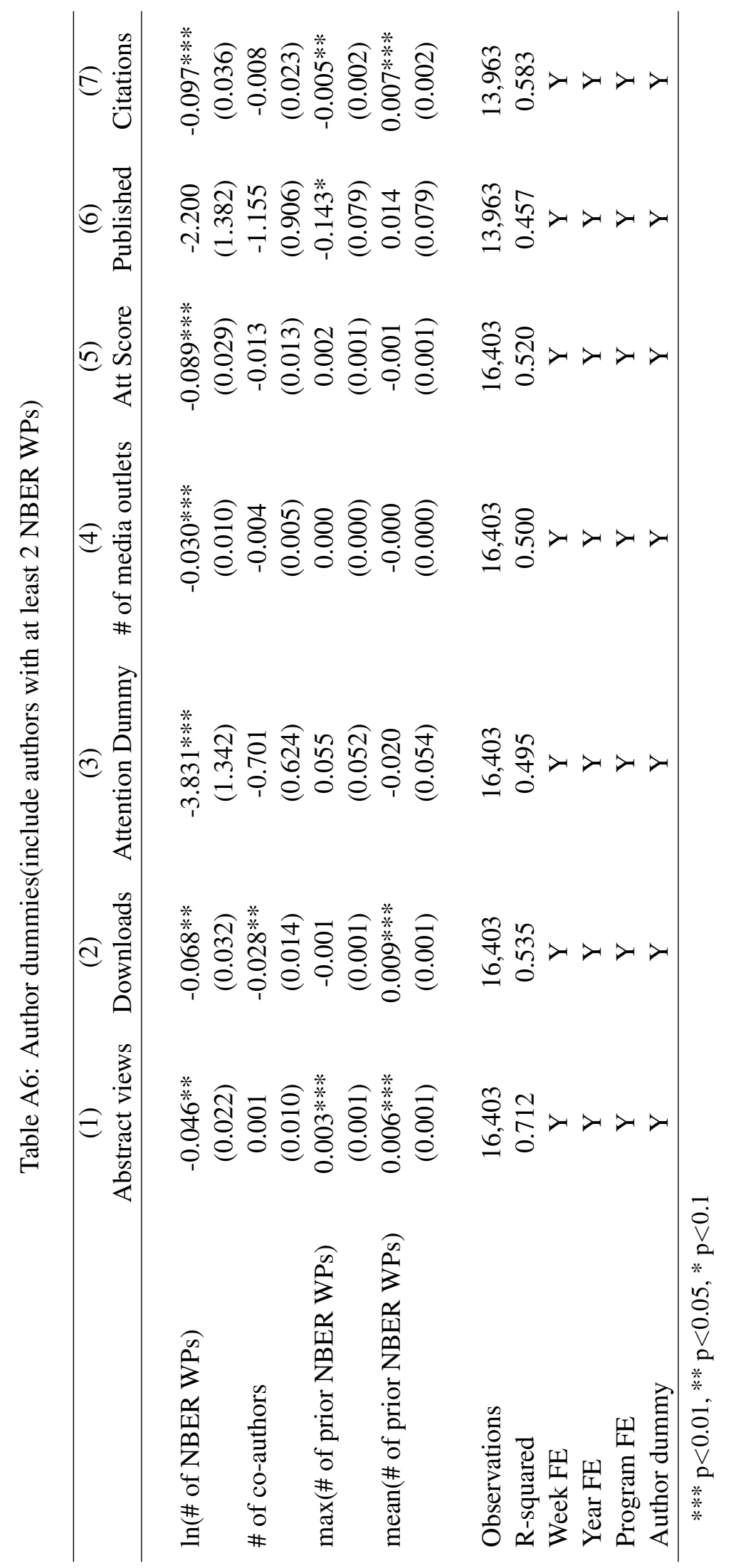




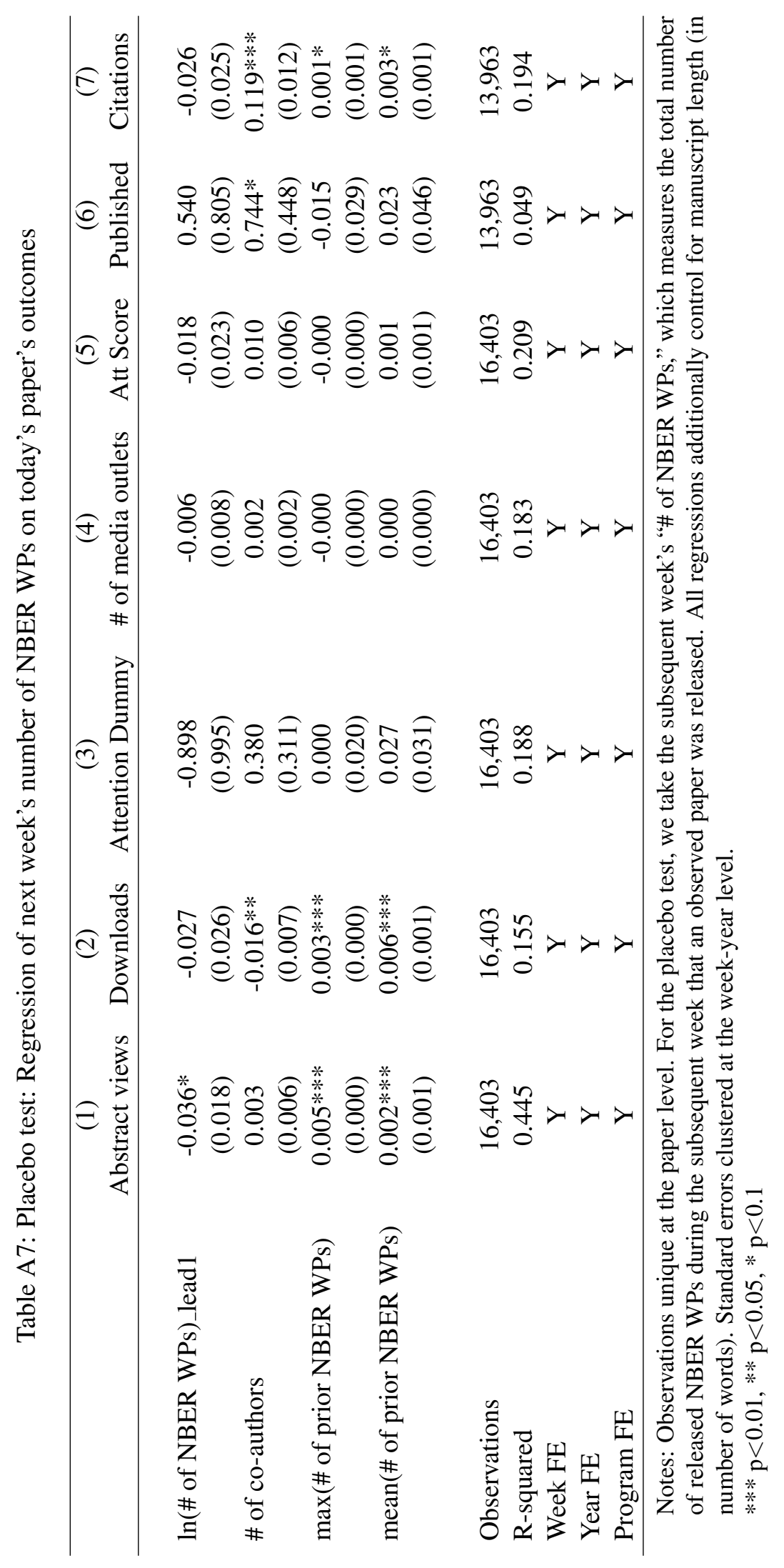




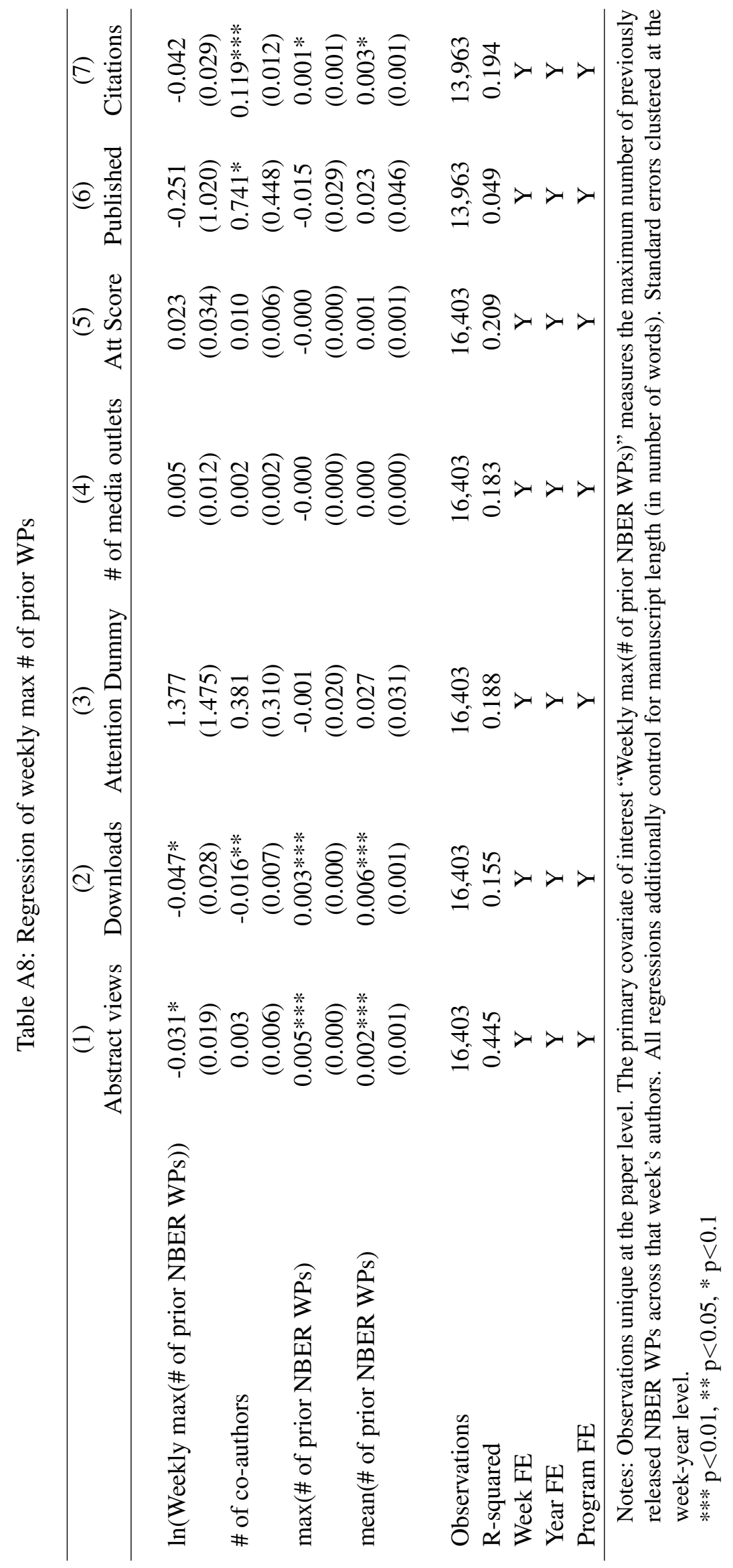


Figure A1: Residuals from regression of weekly \# of NBER WPs on week and year fixed effects

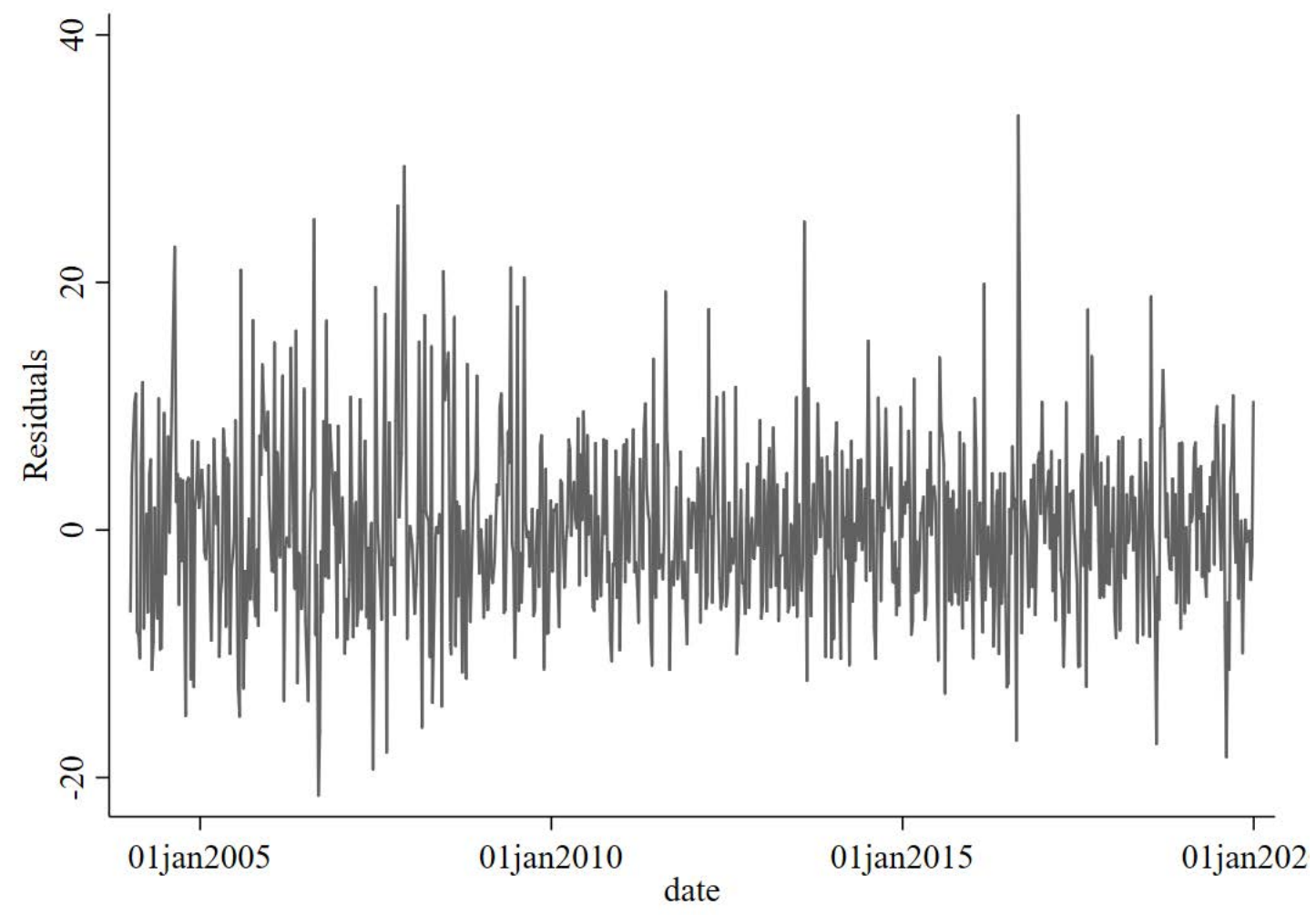


Figure A2: Impacts of number of weekly NBER WPs dissipate over time

(a) $\ln ($ Abstract views)

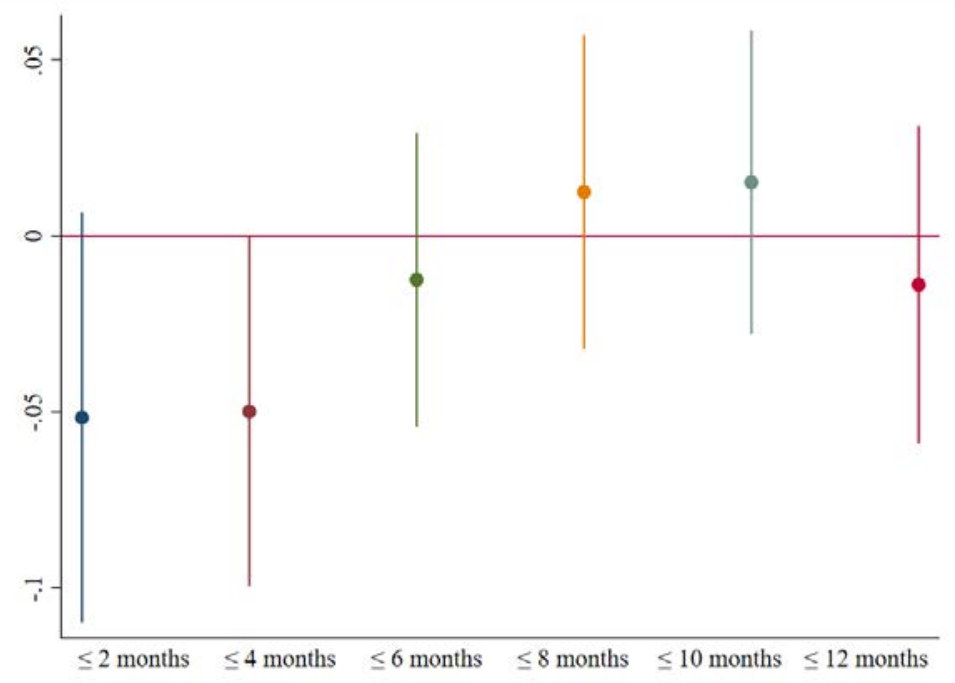

(b) $\ln$ (Downloads)

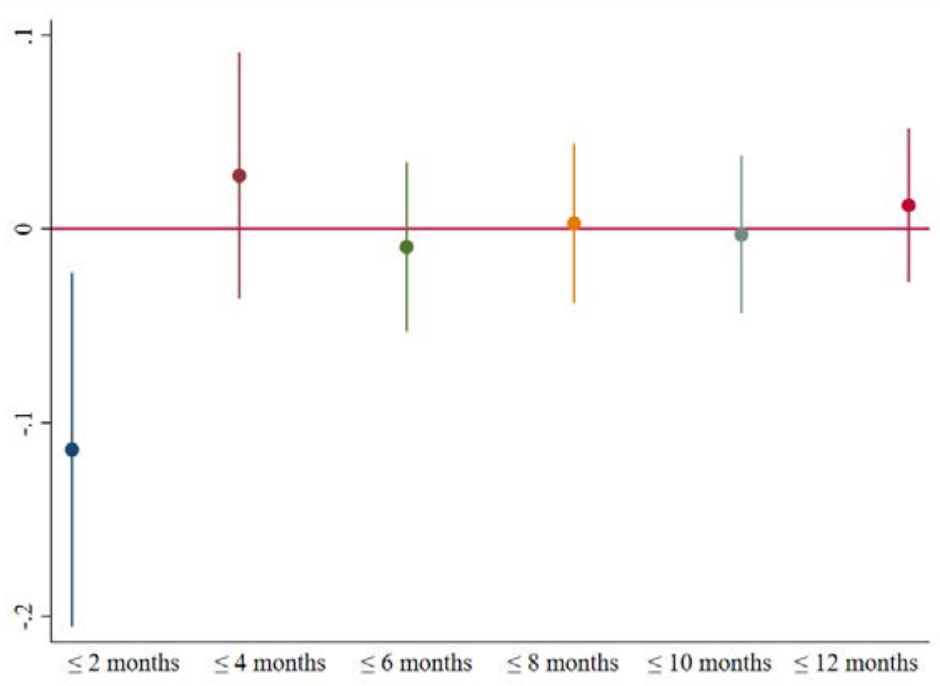

Notes: Each point reflects a separate regression where the outcome differs by the time frame of accumulated abstract views or downloads. For example, the first point in (a) comes from specification (1) where the outcome is the log of abstract views within the first two months of the paper's release. The second point covers abstract views within four months of the paper's release. 95\% confidence intervals included. 